\title{
Diaphragmatic Breathing Exercise in Children
}

\author{
Cristina Maria Santos Calmon', David Luiz Góes', Diana Guimarães de Oliveira Bermudez', Renata Maba Gonçalves', \\ Tayná Castilho', Camila Isabel Santos Schivinski
}

\begin{abstract}
Introduction: Some studies conducted in adult and pediatric population, show the benefit of diaphragmatic breathing exercise for individuals with asthma, cystic fibrosis and even in cases of vertigo. Thus, this literature review paper aims to gather and present scientific evidence on the use of diaphragmatic breathing exercise as a therapeutic strategy in the children diseases. Objective: to present scientific evidence about diaphragmatic breathing exercise as in children's affections. Method: Science Direct, MEDLINE, SciELO, Portal CAPES, PubMed and Bireme, considering the published articles from 1956 to 2016, searched through the descriptors Ciências da Saúde (DeCS): "physical therapy", "pediatric", "children", "breathing" and "diaphragmatic breathing". Was also consulted the bibliographic Universidade do Estado de Santa Catarina (UDESC). There was included the texts related to treatments and trials about diaphragmatic breathign exercise as a therapeutic strategy in pediatrics. Results: Were selected eleven journal articles and one dissertation of course compatible with the established criteria. Conclusions: The publications board the diaphragmatic breathing exercise in premature children, cystic fibrosis, asthma, mouth breathing syndrome, neuromuscular diseases, chronic functional constipation and dysfunctional voiding. Conclusion: This resource has presented positive results in some clinic situations, but are required more investigations about the effects of this therapeutic strategy in children.
\end{abstract}

Keywords: physiotherapy, child, diaphragm.

Study done in Physical Therapy Course of the Universidade do Estado de Santa Catarina (UDESC) - Centro de Ciências da Saúde e do Esporte (CEFID).

\section{INTRODUCTION}

Breathing is the first vital function developed for the occasion of birth, establishing itself as one of the most important of the body ${ }^{1}$. This process is a rhythmic motor action, comprising the inspiration and expiration steps. The first is due to the contraction of the inspiratory muscles, and expiration is passive, promoted by the retraction elastic pressure of the lungs and chest cavity ${ }^{3}$.

The main muscles working in inspiration are the external intercostals and the diaphragm. The diaphragm is responsible for about $70 \%$ of vital capacity and mostly consists by type I muscle fibers ${ }^{3-4}$. When there is tension of diaphragmatic muscle fibers during inspiration, occur the descent of the diaphragmatic dome which pushes the visceral mass and moves the abdomen to out, besides the rising of the ribs that provide for the expansion of the lower thoracic region ${ }^{5}$.

Therefore, the rib cage and abdomen move as an unit during quiet breathing, in the dependence on the pressures developed in these compartments and their respective compliances ${ }^{4}$. This conjunct action is denominated thoracoabdominal movement.

In healthy individuals, positioning changes cause alterations in thoracoabdominal contribution. During the dorsal position, there is predominance of diaphragm action, and in the upright position there is the recruitment of the thoracic musculature ${ }^{6}$. In addition to these physiological differences, changes in breathing pattern and thoracoabdominal movement are relevant factors in the presence of lung impairment, and may be consequences of a mechanic, physiological or psychological dysfunction ${ }^{1-6}$.

According to Courtney (2009), breathing becomes dysfunctional when the person is unable to breathe efficiently. The loss of respiratory function affects the lives of the people, unbalancing homeostasis and creating symptoms which may compromise the health ${ }^{7}$.

In this line, symptoms such as lack of breath, chest pain, anxiety, dizziness, and fatigue are mainly the result from the functional respiratory problems, such as hyperventilation, instability and respiratory irregularity, frequent sighing and breathing pattern predominantly apical instead of diaphragmatic breathing effort ${ }^{8}$. In this context, the correction of breathing disorders and improvement of its functions is the responsibility of respiratory therapy ${ }^{9}$.

Among the approaches used by physical therapy there is diaphragmatic breathing, which consists of making inspirations

Corresponding author: Tayná Castilho. Rua Paschoal Simone, 358 - Coqueiros - CEP: 88080-350 - Florianópolis - SC - Tel.: $3321-8600$. E-mail: taynacastilho@hotmail.com ${ }^{1}$ Universidade do Estado de Santa Catarina, Florianópolis (SC), Brasil

Financial support: There is none.

Submission date 21 July 2016; Acceptance date 14 November 2016; Publication online date 20 December 2016 
using only the abdominal wall and reducing the movement of the upper thoracic region, with a volume normal current and passive expirations ${ }^{10}$. Patients with respiratory distress can benefit from this technique positions, such as sitting or standing, which optimize the stress-length relation of diaphragm, facilitating contraction ${ }^{11}$.

Some studies conducted in adult and pediatric population, show the benefit of diaphragmatic breathing exercise for individuals with asthma, cystic fibrosis and even in cases of vertigo ${ }^{12-13-14}$.

Thus, this literature review paper aims to gather and present scientific evidence on the use of diaphragmatic breathing exercise as a therapeutic strategy in the children diseases.

\section{METHOD}

\section{SOURCES OF DATA}

This is a review article using the following electronic databases: Science Direct, MEDLINE, SciELO, Portal Capes, PubMed, Bireme and PEDro. The keywords, used to search for articles, according to the Descriptors Health Sciences (DeCS), consulted in isolation or combined in different ways to each other, were: "fisioterapia respiratória", "pediatria", "crianças", "respiração", " respiração diafragmática" and their corresponding terms in the English language "physical therapy ", "chest physiotherapy", "pediatrics", "children", "breathing", "diaphragmatic breathing". The bibliographic collection of the State University of Santa Catarina (UDESC) was also consulted.

Among the identified publications, the Portuguese and English were selected, published between 1956 and 2016, involving literature reviews, treatments and clinical trials related to the use of diaphragmatic breathing as a therapeutic strategy in the general pediatric context or directed to children lung diseases.

\section{RESULTS}

\section{DATA SUMMARY}

The search in the databases identified 2359 articles, but only five national articles were included in this review, six international articles and one thesis (Figure 1). This material was characterized by presenting studies that prioritized normal and altered respiratory function, due to some childhood respiratory disease as well as studies that evaluated the use of diaphragmatic respiratory training (diaphragmatic exercise) as a physiotherapeutic action in respiratory diseases in children, combined or not with other physiotherapeutic interventions. Most of the studies were conducted in patients with respiratory diseases such as asthma and cystic fibrosis, in addition to conditions such as prematurity and mouth breathing syndrome.

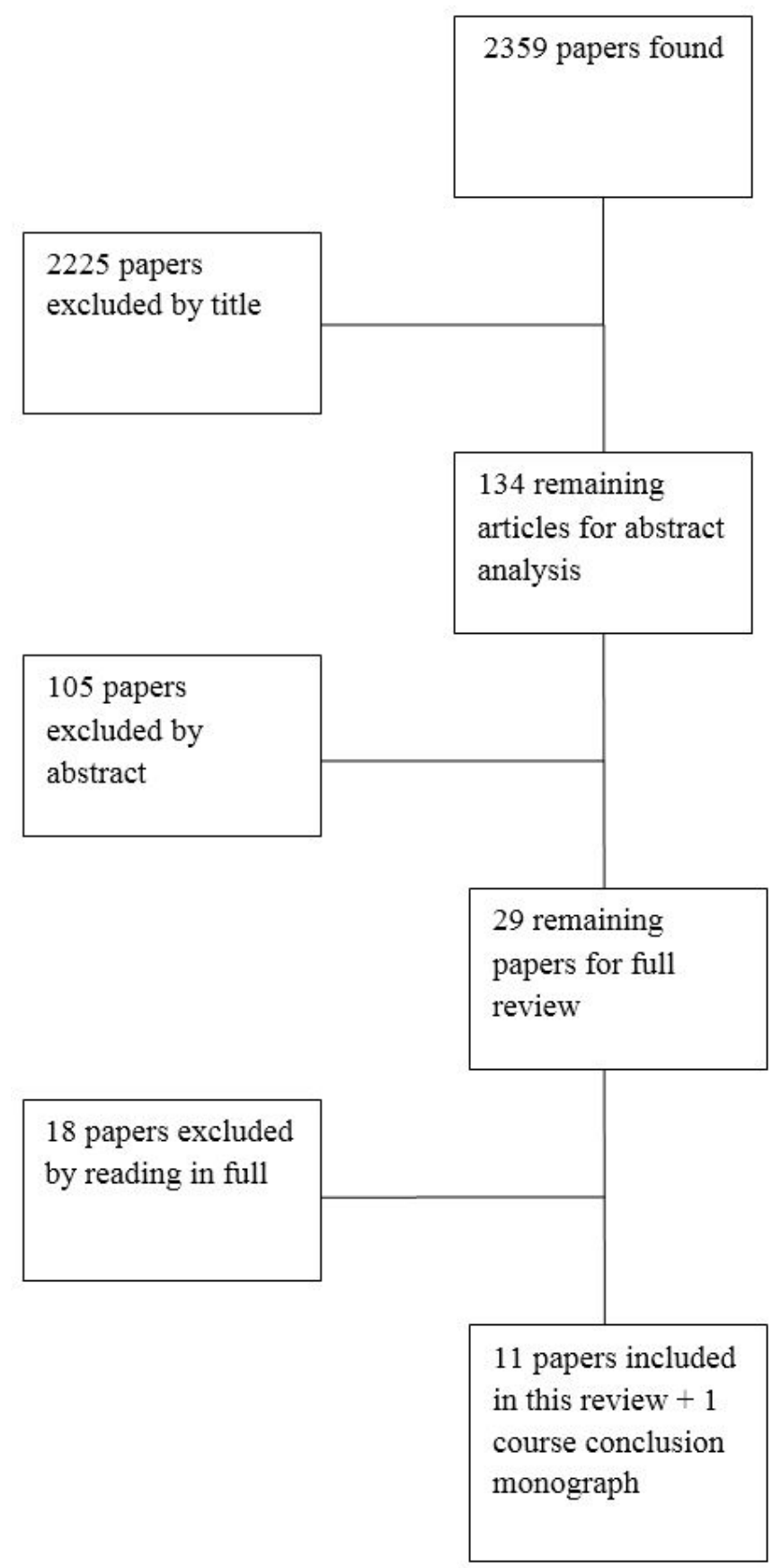

Figure 1 - Diagram of the process conducted for selection and inclusion of studies.

It was observed that much of the literature discourse about the structure and function of diaphragm in breathing. In this line, some clinical situations present specificities regarding to the commitment of diaphragmatic breathing, such as: premature infants, chronic respiratory diseases (asthma and cystic fibrosis), mouth breathing syndrome, neuromuscular diseases, as well as and chronic functional constipation and urinary dysfunctions. These are the conditions under which scientific papers are conducted. 


\section{DISCUSSION}

\section{Premature children}

The premature child is very susceptible to develop respiratory insufficiency due to its anatomical, physiological and immunological characteristics. They present an atrophic or undeveloped diaphragm, which is subject to early fatigue in situations of increased work of breathing, in which this is one of the reasons for the high prevalence of sleep apnea in premature infants ${ }^{15}$. Despite knowledge about this vulnerable respiratory pattern, the application of resources and techniques directed to the diaphragm muscle is restricted in this population.

Facilitation strategies and manual support are proposals in order to improve the capacity of the respiratory muscles through the adaptation of thoracoabdominal biomechanic ${ }^{16}$. In this sense, the Rebalancing Thoracoabdominal method (RTA) proposes the recovery of synergism between the thorax and the abdomen, through the structuring of biomechanical ventilation arrangements which favor pulmonary ventilation and incorporate a breathing with minimal effort to sensory motor activity suitable to the chronological age of the patient ${ }^{16}$.

Demonstrating that the RTA method minimizes the e breathing effort, a controlled clinical trial, randomized of Roussenq et al (2013), performed the RTA in premature newborns (NB). In NB who underwent the RTA it was found a significant decreasing in respiratory rate and dyspnea, analyzed by the Bulletin of Silvermann-Andersen ${ }^{17}$.

\section{Cystic fibrosis}

In patients with cystic fibrosis, respiratory mechanics is changed due to bronchial obstruction, which causes the diaphragm is lowered and come into mechanical disadvantage, which favors the use of accessory muscles ${ }^{18}$.

In these patients, as mentioned in the booklet of the International Physiotherapy Group for Cystic Fibrosis (IPG/CF), some techniques are applied in order to mobilize and remove excess bronchial secretions, such as the Active Cycle of Breathing Techniques (ACBT) ${ }^{19}$. The active cycle of breathing components are: respiratory control, exercises for chest expansion and the positive expiratory pressure technique ${ }^{12}$, being the first intervention which should be emphasized in the cycle. It is a sequence of diaphragmatic breaths, or diaphragm exercises, which is considered the standby period of the most active parts of the cycle.

This technique has a good acceptance in relation to the mobilization of secretions, especially when patients have pulmonary exacerbation ${ }^{20-21}$. However, the studies do not addresses what are the effects of diaphragmatic breathing exercise, which compound the ACBT, in cystic fibrosis individuals, as they have changes of respiratory mechanics. Thus, it is relevant the conduct of studies which analyze the isolated effects of diaphragmatic breathing, in the recovery and maintenance of thoracoabdominal mechanics.

\section{Asthma}

Asthmatic patients present impairment in the two phases of breathing. The inspiration increases and becomes more superficial, and the expiration is longer and ineffective, which generates the picture of pulmonary hyperinflation. The ventilatory mechanics changes due to the lowering of the diaphragmatic dome and reducing of its movement during respiration, damaging the basal ventilation ${ }^{22}$.

Guimarães (1983) affirm that the use of diaphragmatic breathing exercises improves respiratory function in asthmatic children ${ }^{22}$. This technique helps to improve the movement of the chest and distribution of ventilation, making a most economical breathing, since the diaphragm is largely responsible for the chest expansion in normal breathing ${ }^{22-23}$.

The Paulin et al (2001) study reported the case of a child 11 years diagnosed with asthma, which was submitted to respiratory therapy. One of the conduct purposed to that patient was the achievement of diaphragmatic reeducation in the supine position and lateral decubitus right and left. As a result of this treatment program, there was control of respiratory crises, improved life quality and ability to perform life daily activities (LDA). The authors affirm that the exercises with breath control, in addition to assist in rhythm and respiratory flow, favor pulmonary ventilation and assist in airway clearance and sputum secretion ${ }^{24}$.

Another analytical study, randomized trial, examined the effects of a physical therapy program consisting of inspiratory muscle training (IMT) and respiratory exercises on muscle strength, peak expiratory flow (PEF) and severity variables in 50 children with asthma, which they were divided into control group and IMT group. Breathing exercises consisted of fractionated inspiration, pursed lips and diaphragmatic breathing, focusing on rehabilitation and respiratory awareness. A significant increase in the maximum respiratory pressure values (MIP and MEP), providing an improvement in airway obstruction, evidenced by PEF and severity variables ${ }^{25}$. The authors attributed the positive outcome of the MIP, not only to IMT, but also to use of breathing exercises in which, probably, promote awareness and respiratory rehabilitation, leading to a biomechanical readjustment and specific training of desired muscle ${ }^{25}$.

\section{Mouth Breathing Syndrome}

In mouth breathing children, there is a change in breathing capacity, which may cause atrophy in the respiratory functional muscles, sagging and abdominal protrusion ${ }^{27}$. Cardoso and Montemezzo (2005) found in a study with eleven children diagnosed with this syndrome, significant increase in respiratory muscle strength after respiratory therapy, which included ventilatory awareness exercises, postural correction 
and aerobic exercise, in which the first procedure appears to refer the exercise diaphragmatic ${ }^{27}$.

In the study by Correa and Bérzin (2008), 19 children with syndrome of mouth breathing were evaluated with surface electromyography before and after a physical therapy program, in which consisted in stretching and strengthening exercises on Swiss Ball, associated with diaphragmatic breathing with manual stimulation. The aim of the study was to evaluate the recruitment of cervical muscles during nasal breathing, and there was a significant reduction in muscle action after physiotherapy treatment ${ }^{28}$.

\section{Neuromuscular diseases}

Respiratory complications in patients with muscular dystrophy involve an alteration of respiratory muscles which change the respiratory mechanics, with reduced ventilation and tidal volume, ineffective cough and commitment of the other variables of the breathing pattern, which determine the development of pneumonia and respiratory failure ${ }^{29-30}$.

Thus, Siegel (1975) affirm that when patients use effectively the diaphragm during breathing, less muscle work is required for proper ventilation, therefore the respiratory function in children with muscular dystrophy may be improved with emphasis on realization of diaphragmatic breathing ${ }^{31}$. Despite this observation, there are few papers reporting or investigating this relation.

\section{Chronic functional constipation and micturition dysfunction}

The superficial and deep abdominal muscles, in addition to the diaphragm and pelvic floor muscle, form a unit which regulates evacuation and stimulate peristalsis ${ }^{32}$. Thus, the combination of exercises that stimulate and relax the abdominal muscles, which indirectly act on the pelvic floor, associate with diaphragmatic breathing, may help gut contraction and bring relief to patients with chronic functional constipation.

The randomized controlled trial of Silva and Motta (2013) aimed to verify the effect of abdominal muscle training, abdominal massage and diaphragmatic breathing in pediatric patients with chronic functional constipation. Patients between four and 18 years of age were randomized to the physiotherapy group or medical treatment group. The medical treatment group was subjected to doses of laxatives, high fiber diet, intake of water and sphincter control, and the physiotherapy groups associated medical treatment to a physical therapy protocol. Each intervention was described in detail, including diaphragmatic breathing. A higher frequency of evacuation in physiotherapy group after six weeks of treatment was observed ${ }^{33}$.

Zivkovic et al (2012) conducted a research in children with micturition dysfunction, in order to investigate the function of the abdominal and pelvic floor training. The diaphragmatic breathing exercise was inserted in the treatment protocol, in which it was extremely described, as well as the previous study. After a year of treatment most children did not present urinary incontinence, nocturnal enuresis and urinary tract infections. The authors affirm that the pelvic floor exercises and diaphragmatic breathing are simple and may be applied in children over five years, in addition, the help to relax the abdominal muscles, influencing in urination and defecation ${ }^{32}$.

\section{Final considerations}

Most studies address physical therapy programs, including various features and physical therapy techniques, in which the diaphragmatic breathing exercise is one of conducts used in treatment. It is necessary to develop research that addresses this intervention in an isolated way in children. Also, in most studies, there is not a detailed description of this technique.

Although there is no much evidence on the effects of this therapy, this is widely used in day-to-day professional and some authors recognize its importance in the adaptation of the thoracic and abdominal biomechanics and its effect of enhancing the strengthening of respiratory muscles ${ }^{25}$, in addition to favor ventilation and auxiliary in clearing in airway ${ }^{24}$.

It is also observed that the application of diaphragmatic breathing exercise is not limited to individuals with respiratory impairment. It was identified two studies which used this technique in order to help in maintenance of the pelvic floor.

\section{CONCLUSION}

This literature review on the diaphragmatic breathing exercises in children with respiratory disorders suggests that this is an important therapeutic strategy for patients in different clinical conditions, especially in patients with asthma, cystic fibrosis, mouth breathing syndrome or who have alterations of thoracoabdominal mechanical. Furthermore, it is noteworthy that it is necessary further researches on the effects of this treatment strategy in children, to complement and evidence the indication of that resource in children as well as establishing a technical standardization.

\section{CONTRIBUTION OF EACH AUTHOR}

CMSC, DLG and DGOB: search for the papers and article production. RMG, TC and CISS: production and article formatting.

\section{CONFLICTS OF INTEREST}

Nothing to declare.

\section{REFERENCES}

1. Clifton TS, Rowley J. Breathing pattern disorders and physiotherapy: inspiration for our profession. Phys Ther Rev 2011; 16:75-86.

2. Feltrim MIZ, Jardim JRB. Movimento toracoabdominal e exercícios respiratórios: revisão da literatura. Fisioter Pesqui 2004; 11:105-113.

3. Presto BLV, Presto LDN. Fisioterapia respiratória. 4th ed. Rio de Janeiro: Elsevier; 2009. 
4. Sarmento GJV. O ABC da fisioterapia respiratória. Barueri: Manole; 2009.

5. De Troyer, A.; Estenne, M. Functional anatomy of the respiratory muscles. Clin Chest Med, 1988; 9:175-193.

6. Franco SS, Bardi PN, Grinberg M; Feltrim MIZ. Estudo do padrão respiratório e movimento toracoabdominal em valvopatia mitral. Arq Bras Cardiol, 2012; 99:1049-1055.

7. Courtney R. The functions of breathing and its dysfunctions and their relationship to breathing therapy. Int J Osteopath Med, 2009; 12:78-85.

8. Thomas M, McKinley RK, Freeman E, Foy C, Prodger P, Price D. Breathing retraining for dysfunctional breathing in asthma: a randomised controlled trial. Thorax, 2003; 58:110-115.

9. Schechter MS. Airway clearance applications in infants and children. Respir Care, 2007; 52:1382-1391.

10. Gosselink R, Houtmeyers E. Physiotherapy. In Pulmonary Rehabilitation. Eur Respir Mon, 2000; 13:70-89.

11. Nakagawa NK, Barnabé V. Fisioterapia do sistema respiratório. São Paulo: Sarvier; 2006.

12. Bradley JM, Moran FM, Elborn JS. Evidence for physical therapies (airway clearance and physical training) in cystic fibrosis: an overview of five Cochrane systematic reviews. Respir Med. 2006; 100:191-201.

13. Russell ME, Hoffman B, Stromberg S, Carlson CR. Use of controlled diaphragmatic breathing for the management of motion sickness in a virtual reality environment. Appl Psychophysiol Biofeedback. 2014;39:269-77.

14. Karam M, Kaur BP, Baptiste AP. A modified breathing exercise program for asthma is easy to perform and effective. Journal of Asthma, 2016.

15. Piva JP, Garcia PCR, Santana JCB, Barreto SSM. Insuficiência Respiratória na Criança. J pediatr, 1998; 74:99-112.

16. Coelho R, Mondo JMNS, Assumpção MS, Gonçalves RM, Schivinski CIS. Lactentes cardiopatas submetidos aos apoios do método ReequilíbrioTóraco-Abdominal (RTA). Ter Man. 2012; 10:154-160.

17. Roussenq KR, Scalco JC, Rosa GJ, Honório GJS, Schivinski CIS. Reequilíbrio tóraco-abdominal em recém-nascidos prematuros: efeitos em parâmetros cardiorrespiratórios, no comportamento, na dor e no desconforto respiratório. Acta Fisiátr. 2013; 20:118-123.

18. Mcilwaine M. Chest physical therapy, breathing techniques and exercise in children with CF. Paediatr Respir Rev. 2007; 8:8-16.

19. Cystic Fibrosis Worldwide. International Physiotherapy Group for Cystic Fibrosis. 2009; Available from: <http://www.cfww.org/ipg-cf/>.
20. Pryor JA, Tannenbaum E, Scott SF, et al. Beyond postural drainage and percussion: Airway clearance in people with cystic fibrosis. J Cyst Fibros. 2010; 9:187-192.

21. Phillips GE, Pike SE, Jaffé A, Bush A. Comparison of active cycle of breathing and high-frequency oscillation jacket in children with cystic fibrosis. Pediatr Pulmonol. 2004; 37:71-75.

22. Guimarães MLLG. Fisioterapia na asma brônquica. Pediat. 1983; 5:33-37.

23. Postiaux G. Fisioterapia respiratória pediátrica - o tratamento guiado por ausculta pulmonar. $2^{\text {nd }}$ ed. Porto Alegre: Artmed; 2004.

24. Paulin E, Favoreto PB, Vidotto CC. Benefícios da Fisioterapia respiratória na Asma. Relato de um caso. Arq Ciênc Saúde Unipar. 2001; 5:149-154.

25. Lima EVNCL, Lima WL, Nobre A, Santos AM, Brito LMO, Costa MRSR. Treinamento muscular inspiratório e exercícios respiratórios em crianças asmáticas. J Bras Pneumol. 2008; 34:552-558.

26. Ram FSF, Holloway EA, Jones PW. Breathing retraining for asthma. Respir Med. 2003; 97:501-507.

27. Cardoso BR, Montemezzo D. Avaliação da Força Muscular Respiratória em crianças portadoras da Síndrome do Respirador Oral. (Monografia de Conclusão do Curso). Universidade do Sul de Santa Catarina; 2005.

28. Corrêa ECR, Bérzin F. Temporomandibular disorder and dysfunctional breathing. Braz J Oral Sci. 2008; 3:498-502.

29. Pontes JF, Ferreira GMH, Fregonezi G, et al. Respiratory muscle strength, nutritional and postural profile in children with neuromuscular diseases. Fisioter mov. 2012; 25:253-261.

30. Lo Mauro A, D'Angelo MG, Romei M, Motta F, Colombo D, Comi GP, et al. Abdominal volume contribution to tidal volume as an early indicator of respiratory impairment in Duchenne muscular dystrophy. Eur Respir J. 2010; 35:1118-1125.

31. Siegel IM. Pulmonary problems in Duchenne muscular dystrophy. Diagnosis, prophylaxis, and treatment. Phys Ther. 1975; 55:160-162.

32. Zivkovic V, Lazovic M, Vlajkovic M, Slavikovic A, Dimitrijevic L, Stankovic I, et al. Diaphragmatic breathing exercises and pelvic floor retraining in children with dysfunctional voiding. Eur J Phys Rehabil Med. 2012; 48:413-421.

33. Silva CAG, Motta MEFA. The use of abdominal muscle training, breathing exercises and abdominal massage to treat paediatric chronic functional constipation. Colorectal Dis. 2013; 15:250-255. 